\title{
ISO 50001: Are the Auditors Equipped Enough?
}

\author{
Avijit Choudhury \\ AGM-Energy Services, Enfragy Solutions India Pvt. Ltd., New Delhi, India \\ Email: avijit.choudhury@enfragy.com
}

Received October 3, 2012; revised November 14, 2012; accepted December 4, 2012

\begin{abstract}
This paper tries to address the issue of expertise and awareness level of ISO-50001 [1] certification auditors in judging the efficacy of existing energy management (EnMS) and suggest the methodology to ensure continual improvement in EnMS. This article also tells about the need of thorough understanding of legal \& other mandatory requirements which need to be addressed properly before framing the energy policy and setting up objectives \& targets for the organization. Particularly SMEs, while implementing any standard or adopting any new system, largely depend on the consultant/ system auditor because of their limited knowledge and resources. In such cases the auditors need to play a larger role by making appropriate ENCON recommendations and guide them how to achieve the compliance. Further in India, most of the companies have got poor metering system. Even crucial energy data like flow rate of LPG, natural gas, FO, steam etc are quoted from judgment or past experience. Meters are not there to measure motor power, liquid temp or gas prss. In such cases auditors need to guide the clients how to establish the energy monitoring \& targeting system and how to establish proper M\&V (Measurement \& Verification) protocol. In nut shell the ISO-50001 auditor needs to play the role of a friend, philosopher \& guide to ensure that at the end of the day his client has complied with all the energy regulations and at the same time achieved some significant reduction in energy consumption.
\end{abstract}

Keywords: ISO-50001; Energy Performance Indicators; Measurement \& Verification Protocol; Certification Audit; Normalization of Energy Baseline; Specific Energy Consumption

\section{Introduction}

In June, 2011 "International Organization for Standardization” (ISO) launched another global standard ISO-50001 [1] for "Energy Management System” EnMS. Industry is very much familiar with ISO-9001, ISO-14001 etc. but not much familiar with ISO-50001. ISO standards are basically for different kind of management systems. For example ISO-9001 speaks about Quality management and ISO-14001 for environmental or emission management system. It is to be understood that this latest standard (ISO-50001) is also a management system but is different from earlier standards.

Unlike other two standards, this standard is more quantitative rather than qualitative. ISO-9000was introduced mainly to ensure that customers should not get faulty or defective material/service by any chance and there is no delay in the delivery schedule. How you generally measure the efficacy of this quality system? It is often done by counting the reduction in numbers of "Customer Complains" before and after implementation of ISO-9000 standard. Now let us see how ISO-50001 is different from this.

\subsection{ISO-50001: More and More Quantitative Rather than Qualitative}

To measure the outcome and success of EnMS one need to look at the followings.

1) What is the amount of total electricity consumed?

2) What is the consumption pattern of other energy like Coal, gas, oil etc.?

3) What are the efficiency of different equipments like boiler, furnace, pumps, blowers, cooling tower, transformers etc.?

4) What is the specific energy consumption (SEC)?

5) What is the current baseline and so on?

In simple words the energy performance indicators (EnPI) of all major equipments and sub-systems have to be defined and are to be measured, monitored and analyzed on regular basis to ensure continual improvement of EnMS as per PDCA (Plan-Do-Check-Act) cycle [1]. Thus the standard has said that the MR (Management Representative) should have requisite skill of calculation and analysis of energy data. Along with the MR, the auditor should also have complete knowledge of mass and energy balance and efficiency calculation of various 
equipments/systems. The auditor should have exposure of different industries like Power Plant, Refinery, Petrochemical, Textile, Iron \& Steel, Fertilizer etc to understand the various need and priorities of different sectors. While a power plant shall be interested in "Plant Heat Rate" and "Plant Load Factor", a textile plant will focus on "Number of Counts", "UKG-Thermal \& Electrical”. Presently in India it has been observed that the certifying bodies have not recruited qualified energy auditors and have trained them in this standard to accomplish the task. Rather they have engaged their existing ISO-14001 or OSAS-18001 auditors for this job who may not have the requisite energy background.

\subsection{Indian Scenario in ISO-50001 Certification}

In India, so far, more than 30 companies have got ISO50001 certification. But questions can be asked in most of the cases:

1) How these companies have got certifications so quickly?

2) Is there any reduction in their electricity demand, or monthly electricity bill?

3) Have they substituted any of their primary energy like coal, gas oil etc with renewable or alternative energy?

4) Have they checked the efficiency of different equipments and segregated the inefficient lot?

5) What is the specific energy consumption (SEC) at present and what they are aiming at?

6) How SEC varies with capacity utilization factor?

7) Have they recorded the current energy baseline?

8) Have they set up data measurement and monitoring system?

It has been observed that some companies have got certification but have not addressed many of the above issues. Then how to judge whether their energy management system is in line or not? EnMS is reflected in reduction of SEC (specific energy consumption) or achieving target baseline i.e. both are in numbers. Have all those companies shown improvement in numbers? Or have the auditors really waited for that long period to check whether the recommended EnMS is correct and it is producing desired result. To counter this question some of the auditors have given argument that "Certification is given on intention rather than action". That's why some companies who have submitted a metering plan in their energy manual have got the certification on the assumption that once the metering system is in place proper monitoring shall be done. However it was not checked what was the capital expenditure required for this metering system, whether it was approved by their finance department and how long it will take to complete the entire installation process. Therefore in most of the cases, it is found that the metering system is on paper only and its implementation is either put on abeyance or cancelled on some technical or financial ground.

\section{Challenging Issues}

While preaching the concept of energy management system \& ISO-50001, the author had traveled across the industries and interacted with different people. Given below some of the challenging issues which the author encountered with. The author felt that these issues should be addressed by the Certification Auditors before issuing the ISO-50001 certificate.

1) Correct definition of energy baseline [2]: Sometimes plant people commit mistakes by wrongful inclusion or exclusion of data. This happens for complicated plant boundaries and overlapping functions. For example, one plant operates hundreds of vehicle to transport their staff from the colony. The vehicle runs on diesel. Diesel is also used in the plant to run DG sets, dryer, furnace and other equipments. However while making the diesel accounting the transportation part was not excluded and wrongfully added to the baseline. Similarly another plant which built an extra shed as a part of their expansion plan, included the extra electricity consumption (in the baseline) taken by the wielding machines and other construction equipments. These oversights may happen if proper energy balance is not done or energy review has not been carried out.

2) Energy forecasting: A well managed unit should know the relation between his energy consumption \& production level [3]. A careful study will show that total energy requirement has two parts. One part is fixed energy which is constant irrespective of production level. The other part is variable one which is proportional to the production level. However this proportionality may not necessarily be a linear function. Such Energy-Production graph Figure 1 is essential in EnMS to assess the energy performance in case of widely varied production level and also to plot CUMSUM curve Figure 2 for energy performance analysis.

3) Defining variables affecting EnPI: For every EnPI the variables are to be defined, established \& recorded. The energy manual should have listing of all such variables. For example plant generally logs boiler efficiency. If at any point of time efficiency value is low, Energy Manager quickly cludes that boiler is not being operated efficiently. However boiler efficiency is a function of number of variables which are generally not checked on regular basis.

- Turn-down ratio.

- GCV of fuel.

- Steam quality (dryness fraction).

Similarly, if the effectiveness of cooling tower is low or if the $L / G$ ratio is poor-we should not immediately conclude about the poor performance of cooling tower. It 


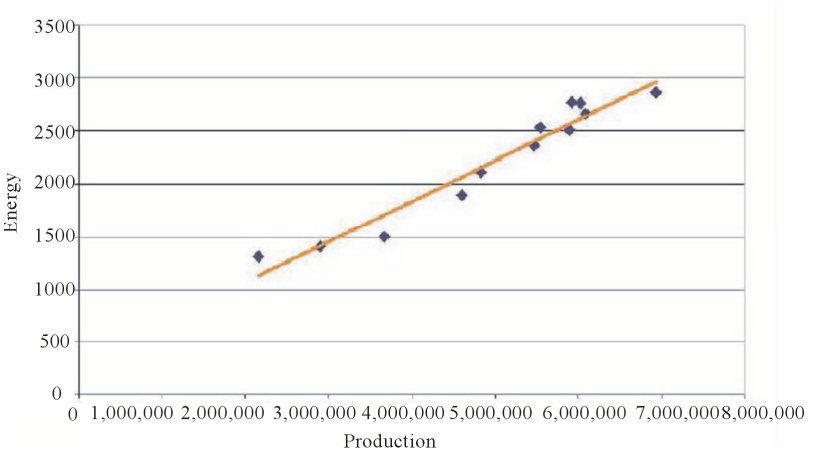

Figure 1. Energy vs. production curve [3].

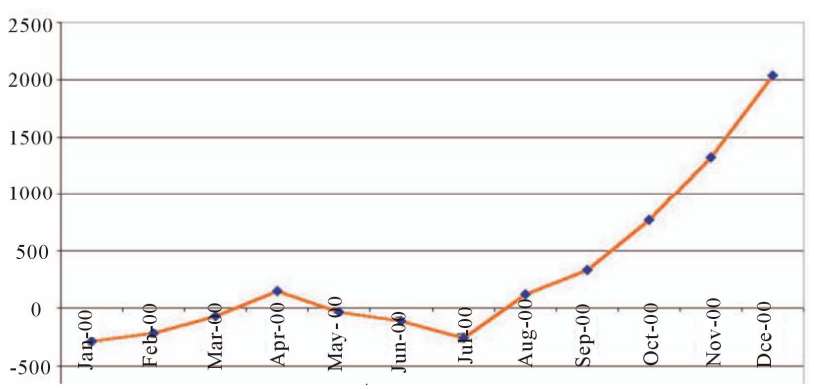

Figure 2. Cumsum chart [3].

is to be membered at the above efficiency parameters are grossly dependent on ambient condition like air temp and its humidity. Sudden change in weather condition can abruptly affect the cooling tower performance. Hence in the cooling tower department, the design parameters such as theoretical dry bulb \& wet bulb temp and designed approach value should be pasted on the wall.

4) Defining SEC in case of multiple products: It is common practice in India, particularly for designated energy consumers [4], to express the energy efficiency of their plant in terms of SEC like ton of oil equivalent (TOE)/Ton of product or $\mathrm{kWh} / \mathrm{Kg}$ of product or $\mathrm{Kcal} / \mathrm{Kg}$ of product. In fact for claiming E-cert (Energy Saving Certificate) determination of SEC is pre-requisite. However along with a major product there can be number of other products. For example the major product of chloralkali plant is caustic soda but along with this it also produces by-products like liquid chlorine, compressed hydrogen and solid flakes Table 1. Similarly a textile plant produces yarn of different counts. Again a cement plant produces different grades of cement like OPC, PPC and PSC.

Then how to define a single baseline based on multiple products?

In such cases all by-products have to be converted into equivalent of major product (with respect to their energy requirement). For example, in case of chlor-alkaliindustry the product equivalence suggested by BEE [5] (Bureau of Energy Efficiency of India) is like this.
Table 1. Product equivalence [4].

\begin{tabular}{|c|c|}
\hline Caustic Soda (Ton) & 1 of equivalent of caustic soda \\
\hline Liquefied Chlorine (Ton) & $\begin{array}{l}0.0615 \text { ton of equivalent of } \\
\text { caustic soda }\end{array}$ \\
\hline $\begin{array}{l}\text { Compressed Hydrogen } \\
\text { (Lakh NM3) }\end{array}$ & $\begin{array}{l}13.889 \text { ton of equivalent of } \\
\text { caustic soda }\end{array}$ \\
\hline Solid Flakes (Ton) & $\begin{array}{l}0.219 \text { ton of equivalent of } \\
\text { caustic soda }\end{array}$ \\
\hline
\end{tabular}

Again for yarn producing textile sector, yarn of all counts needs to be converted in to some standard or reference count for unification of products. Bureau of Energy Efficiency of India [5] has suggested 40 count as the reference count for yarn manufacturing units.

5) Setting up logical targets: In many cases we found that companies declare their energy policy and quantum of reduction even before conducting energy review. For example if a company announces in its energy policy that it will reduce its total energy consumption by $5 \%$ in the next three years cycle then it is not clear how this will be achieved. Company may set the universal target of $5 \%$ energy reduction for all the departments. But this is not logical. Without proper energy review one can never know what is the reduction potential available with various departments. As an example, its steam generation system (boiler) might be functioning well by operating at an efficiency level close to design value. Hence further efficiency improvement in this system might be a very expensive proposition. Whereas it may be found that in compressed air generation system, the compressor is giving 30\% lower FAD (free air delivery) than its design value and there exists $35 \%$ leakage in the compressed air line. Hence this department can easily be given much higher target of energy reduction. Therefore the target setting should be done by forward integration method i.e. find out first the energy saving potential of individual departments and based on this data set up the overall energy saving target of the plant.

6) $\mathbf{M} \& \mathbf{V}$ protocol: This is very important for the plant management to be sure about the authenticity or degree of reliability of the energy data. Preference should be given to reduce the human interference or dependency on data capturing. For example in a coal fed boiler the average fuel feed rate is decided by the amount of coal taken from central store minus the inventory at boiler house. However to achieve precision in feed rate data there should be load cell before boiler feeder/hopper where accurate measurement can be recorded

Where there is no online steam flow meter in many cases, the steam flow rate is considered same as the rated flow of the boiler feed water pump. Again it is found that some companies make some arbitrary statement that they have saved 20\% energy in lighting by changing all tube 
lights with CFL or metal halide lamps with LED. Okay fine. But where is the measurement? If there is no separate lighting feeder no measurement could be done to ascertain the quantum of savings. ISO-50001 auditors should ensure that proper Measurement \& Verification protocol is established in the plant and there is separate budgetary allocation for its implementation. It is to be remembered that. "You can't manage what you don't measure”.

\section{Normalization of Baseline [4]}

This is especially important for the designated energy consumersin India who have legal or mandatory requirement of meeting the energy target. The energy performance of the plant may get affected due to several internal \& external factors which are beyond control of the plant management. Some points are highlighted below.

- Capacity utilization: May be affected by less demand, scarcity of raw material, new regulation etc. It is clear from Figure 1 that SEC value will be higher when plant operates at lower production level. Last three years survey data shows that many sectors have shown poor capacity utilization due to various uncontrollable factors like.

- Textile: Lower demand from export market because of slowing down of economy in US \& EU.

- Cement: Lower GDP growth rate of India compared to previous years.

- Ferroalloy: Disruption in raw material supply from mines.

- Power plant: Failure of Coal India to supply guaranteed quota of coal.

- Plant breakdown: May be due to social unrest, strike, accident etc. Plants located in Andhra Pradesh, Chhattisgarh, Jharkhand and other Maoist affected areas are the worst sufferer of unusual closure of production unit due to social unrest. During such period the emergency units of the plant were on and consuming power while there was no output or production. Such behaviour affects the baseline badly and it is recommended to omit those affected days from SEC calculation at the end of the year.

- Change in energy mix: Ratio of use of grid power vs. captive power due to interruption in grid power supply. Plants located in Uttar Pradesh are the worst sufferers of poor grid supply. In India energy baseline calculation methodology suggested by BEE is "Gateto-Gate” concept basis [4]. This means it makes a huge difference in baseline if you produce power (say from coal) in your captive power plant rather than buying it from grid. The reason is-under gate-togate concept the quantum of primary energy (coal in this case) is considered making baseline calculation rather than the electricity produced by CPP. In all such cases the auditor needs to calculate the gross and net heat rate of the CPP to undergo the normalization of baseline.

- Fuel quality: The most affected sector is thermal power plant using coal from different sources. Different parameters of coal like GCV, \% ash (A), \% moisture (M) \& \% hydrogen $(\mathrm{H})$ affect the useful heat available to the boiler. To take care of this situation, BEE has suggested the formula to normalize the station heat rate of thermal power plant [4].

Boiler efficiency $=92.5-[50 \times A+630(M+9 H)]$ GCV; Station heat rate $(\mathbf{K c a l} / \mathbf{k W h})=$ Turbine heat rate/boiler efficiency.

- Depreciation of equipment efficiency over the life cycle: Efficiency of equipment is not constant but reduces over the period of time. If we have the efficiency life cycle curve of major energy consuming equipments then normalization of baseline should be done accordingly. A simple example is membrane \& electrode life of Chlorlkali plant. After consultation meeting with "Alkali Manufacturers Association of India” BEE has suggested that $60 \mathrm{kWh} /$ ton per year is to be added to the specific energy consumption of the baseline year to normalize the baseline SEC at the final accounting year [4]. Similarly a 15 years old boiler may have 10 to $12 \%$ lower efficiency due to reduced $\mathrm{U}$ (over all heat transfer coefficient). In such case a baseline drawn 15 years ago need to be normalized according to the reduced efficiency level.

\section{Conclusion}

From the above it is clear that ISO-50001auditors should be thoroughly conversant with the energy guidelines under different Government notifications, energy audit rules and energy accounting procedure \& practices. They must remember that the main purpose of this standard should not be defeated at any cause. On the other hand the companies should also understand that their main aim is to achieve reduction in SEC and not a mere certificate on a piece of paper. They may jointly seek expert advice from "BEE Accredited Energy Auditor" [5] for critical issues like energy review and normalization of base line to make the EnMS flawless.

\section{REFERENCES}

[1] “International Organization for Standardization,” ISO50001. http://www.iso.org/iso/iso_50001_energy.pdf

[2] Energy Conservation (Amendment) Act, “2010-Ministry of Power."

http://www.powermin.nic.in/acts_notification/pdf/ecact20 01.pdf

[3] "National Certification Examination of BEE for Energy Manager \& Auditor.” 
http://www.emt-india.net/Book1/Book1.htm

[4] Ministry of Power, Government of India, "PAT Notification,” 2012. http://beeindia.in/schemes/schemes.php?id=9
[5] Bureau of Energy Efficiency, "The Apex Body of Energy Conservation \& Energy Efficiency in India.” http://www.beeindia.in/ 